\title{
Small Bowel Obstruction After Ileal Pouch-Anal Anastomosis With a Loop Ileostomy in Patients With Ulcerative Colitis
}

\author{
Hitoshi Kameyama ${ }^{1}$, Yoshifumi Hashimoto ${ }^{1}$, Yoshifumi Shimada ${ }^{1}$, Saki Yamada ${ }^{1}$, Ryoma Yagi $^{1}$, \\ Yosuke Tajima ${ }^{1}$, Takuma Okamura ${ }^{1}$, Masato Nakano ${ }^{1}$, Kohei Miura ${ }^{1}$, Masayuki Nagahashi ${ }^{1}$, Jun Sakata ${ }^{1}$, \\ Takashi Kobayashi ${ }^{1}$, Shin-ichi Kosugi ${ }^{2}$, Toshifumi Wakai ${ }^{1}$ \\ ${ }^{1}$ Division of Digestive and General Surgery, Niigata University Graduate School of Medical and Dental Sciences, Niigata; ${ }^{2}$ Department of \\ Digestive and General Surgery, Uonuma Institute of Community Medicine, Niigata University Medical and Dental Hospital, Niigata, Japan
}

Purpose: Small bowel obstruction (SBO) remains a common complication after pelvic or abdominal surgery. However, the risk factors for SBO in ulcerative colitis (UC) surgery are not well known. The aim of the present study was to clarify the risk factors associated with SBO after ileal pouch-anal anastomosis (IPAA) with a loop ileostomy for patients with UC. Methods: The medical records of 96 patients who underwent IPAA for UC between 1999 and 2011 were reviewed. SBO was confirmed based on the presence of clinical symptoms and radiographic findings. The patients were divided into 2 groups: the SBO group and the non-SBO group. We also analyzed the relationship between SBO and computed tomography (CT) scan image parameters.

Results: The study included 49 male and 47 female patients. The median age was 35.5 years (range, 14-72 years). We performed a 2- or 3-stage procedure as a total proctocolectomy and IPAA for patients with UC. SBO in the pretakedown of the loop ileostomy after IPAA occurred in 22 patients (22.9\%). Moreover, surgical intervention for SBO was required for 11 patients. In brief, closure of the loop ileostomy was performed earlier than expected. A multivariate logistic regression analysis revealed that the 2 -stage procedure (odds ratio, 2.850; $95 \%$ confidence interval, $1.009-8.044 ; \mathrm{P}=0.048$ ) was a significant independent risk factor associated with SBO. CT scan image parameters were not significant risk factors of SBO. Conclusion: The present study suggests that a 2 -stage procedure is a significant risk factor associated with SBO after IPAA in patients with UC.

Keywords: Ulcerative colitis; Ileostomy; Small bowel obstruction

\section{INTRODUCTION}

Small bowel obstruction (SBO) is the most common complication in patients who undergo abdominal surgery. A prior report

Received: December 18, 2016 - Accepted: June 14, 2017

Correspondence to: Hitoshi Kameyama, M.D.

Division of Digestive and General Surgery, Niigata University Graduate

School of Medical and Dental Sciences, 1-757 Asahimachi-dori, Niigata,

Niigata 951-8510, Japan

Tel: +81-25-227-2228, Fax: +81-25-227-0779

E-mail:kame@med.niigata-u.ac.jp

ORCID code: https://orcid.org/0000-0002-1091-9606

(C) 2018 The Korean Society of Coloproctology

This is an open-access article distributed under the terms of the Creative Commons Attribution NonCommercial License (http://creativecommons.org/licenses/by-nc/4.0) which permits unrestricted noncommercial use, distribution, and reproduction in any medium, provided the original work is properly cited. noted that SBO after abdominal surgery occurred in approximately $20 \%$ of the cases [1]. Menzies and Ellis [2] found a much higher proportion (93\%) of patients with postoperative intra-abdominal adhesions at subsequent surgeries. These adhesions are the major cause of a SBO after surgery [3].

In 1978, Parks and Nicholls [4] reported that a total proctocolectomy (TPC) with ileal pouch-anal anastomosis (IPAA) was an effective treatment for patients with ulcerative colitis (UC). In 1980, Utsunomiya et al. [5] described a restorative proctocolectomy with an ileal J pouch for the treatment of patients with adenomatosis coli and UC. This type of surgery is a standard procedure for UC. In most cases, a 2- or a 3-stage procedure with a loop ileostomy is performed to prevent surgical complications, such as leakage of the anastomosis and pelvic abscess. However, the loop ileostomy itself may cause other complications, including skin irrita- 
tion, prolapse, and bowel obstruction [6]. The complication rate of a loop ileostomy in abdominal surgery has been reported to be $5 \%-100 \%$ [7], and SBOs have frequently occurred in patients at a rate of 3\%-9.9\% [8-10]. These rates vary due to the differences in the lengths of follow-up for previous studies. The frequency of a SBO for UC surgery is comparatively higher than that for other abdominal surgeries because of the combined abdominal and pelvic dissection, need for multiple surgeries, and possibly a higher likelihood of septic complications [11]. The incidence of a postoperative SBO in UC surgery is estimated to be 6\%-25.3\% [11-18]. A SBO may lead to a decrease in the quality of life, as well as a longer duration of hospital stay. However, the risk factors associated with a SBO for UC surgery are not well known. Thus, the aim of the present study was to clarify the risk factors associated with a SBO after an IPAA with a loop ileostomy for patients with UC.

\section{METHODS}

We performed a retrospective review of data from hospital records. During the years 1999-2011, 96 patients underwent an IPAA for UC at Niigata University Medical and Dental Hospital. This study is retrospective observational study, carried out by the opt-out method of our institution. All patients underwent a rectal mucosectomy with a hand-sewn IPAA by open surgery. The IPAA has been usually performed in 1,2 , or 3 stages. In the 3 -stage procedure, first, a subtotal colectomy with an end ileostomy/ascending colostomy and setting of the mucous fistula were performed. Subsequently, pouch surgery was performed as a second operation, and the stoma was closed as the third operation. In the 2-stage procedure, a TPC and an IPAA with an ileostomy were performed as the first operation, and the temporary loop ileostomy was closed 1-3 later as the second operation. The pouch shapes used for the IPAA included a $\mathrm{W}$ or a J pouch. The $\mathrm{W}$ pouch's construction was used as the main procedure at our institute $[19,20]$. A stapled pouch construction was also performed for a J pouch surgery. The J pouch's construction was selected when performing an IPAA was difficult because of intra-abdominal adhesion, obesity, a narrow pelvis, and a small-bowel mesentery shortage. As a surgical approach, the 1-stage procedure is not performed at our institution. Therefore, a 2- or a 3-stage procedure was performed in all cases. We have performed the 2-stage operation for UC patients without factors such as poor general condition, poor nutrition, fulminant colitis, and a toxic megacolon. Hence, we selected the 3-stage procedure when the preoperative patient's condition was severe. The optimal stomal placement site was preoperatively marked on the right lower quadrant abdominal wall. Closure of the loop ileostomy was performed 1-3 months after the IPAA.

In this study, a SBO was confirmed by both the presence of clinical symptoms, such as abdominal pain, nausea, vomiting, and no passage of flatus or stool, and abdominal radiographic findings. These clinical diagnostic criteria have been recommended by sev- eral studies $[3,11-13]$. The patients were divided into 2 groups: the $\mathrm{SBO}$ and the non-SBO groups. Clinical variables, including age, sex, height, weight, body mass index (BMI), preoperative serum albumin level, clinical course, surgical indication, total prednisolone dose, pre-IPAA steroid use, pre-IPAA daily prednisolone dose, leukocytapheresis (LCAP)/granulocytapheresis (GCAP) treatment, use of immunomodulatory drugs, post-IPAA steroid use, operating time, blood loss, surgical procedure (2- or 3-stage procedure), stoma rotation, shape of the ileal pouch, and use of an adhesion barrier were compared between the 2 groups. We also analyzed the thicknesses of the abdominal rectus muscle and the subcutaneous fat and the size of the stoma at the skin or fascia level in the 2 groups by using computed tomography (CT) scan images. The thicknesses of the muscle and the fat were measured at the umbilical level by using CT scans. All patients who developed a SBO underwent conservative treatment, such as the cessation of an oral diet and/or the insertion of a transstomal decompression tube.

In this study, we analyzed the risk factors associated with a SBO after an IPAA with a loop ileostomy, namely, during the pretakedown period, in patients with UC. Statistical analyses were performed using the Mann-Whitney U-test or Fisher exact test. A multivariate logistic regression was performed to determine which significant factors from the univariate analysis remained significant. P-values of $<0.05$ were considered to be statistically significant. IBM SPSS Statistics ver. 22.0 (IBM Co., Armonk, NY, USA) was used for the statistical analyses.

\section{RESULTS}

A total of 96 patients underwent an IPAA by open surgery for UC at Niigata University Medical and Dental Hospital between 1999 and 2011. The patients' demographics are shown in Table 1. The median age of the patients was 35.5 years (range, 14-72 years), and the median follow-up period after the IPAA was 108 months (range, 53-192 months). Of these patients, 49 (51.0\%) were male and $47(49.0 \%)$ were female patients. The 1-stage procedure was not performed at our institution. A loop ileostomy was introduced in all cases.

A SBO occurred during the pretakedown of the loop ileostomy after the IPAA in 22 patients (22.9\%). Moreover, surgical intervention was required for 11 patients (Fig. 1). In brief, closure of the loop ileostomy had to be performed earlier than expected. The cause of the SBO requiring surgery was an outlet obstruction in eight patients. In the remaining three patients, the cause of the $\mathrm{SBO}$ was considered to be intra-abdominal adhesion. Furthermore, in the 11 patients, the SBO improved with conservative treatment, such as the cessation of an oral diet and/or the insertion of a transstomal decompression tube (Fig. 2).

According to the univariate analysis, younger age $(\mathrm{P}=0.005)$, male sex $(P=0.028)$, taller height $(P=0.003)$, and a 2-stage procedure $(\mathrm{P}=0.029)$ were risk factors associated with a SBO after 
Small Bowel Obstruction After Ileal Pouch-Anal Anastomosis With a Loop Ileostomy in Patients With Annals of Ulcerative Colitis

\section{Coloproctology Hitoshi Kameyama, et al.}

Table 1. Patients' characteristics $(\mathrm{n}=96)$

\begin{tabular}{|c|c|}
\hline Variable & Value \\
\hline Age (yr) & $35.5(14-72)$ \\
\hline \multicolumn{2}{|l|}{ Sex } \\
\hline Male & $49(51.0)$ \\
\hline Female & $47(49.0)$ \\
\hline Height (cm) & $161(141-183)$ \\
\hline \multicolumn{2}{|l|}{ Disease extent } \\
\hline Total colitis & $88(91.7)$ \\
\hline Left-sided colitis & $7(7.3)$ \\
\hline Proctitis & $1(1.0)$ \\
\hline \multicolumn{2}{|l|}{ Clinical course } \\
\hline Relapsing-remitting & $70(72.9)$ \\
\hline Chronic continuous & $12(1.3)$ \\
\hline Acute fulminating & $14(14.6)$ \\
\hline \multicolumn{2}{|l|}{ Surgical indication } \\
\hline Severe/fulminant & $28(29.2)$ \\
\hline Refractory & $53(55.2)$ \\
\hline Cancer/dysplasia & $15(15.6)$ \\
\hline Total prednisolone dose (mg) & $6,207.5(0-90,000)$ \\
\hline \multicolumn{2}{|l|}{ Pre-IPAA steroid use } \\
\hline Absence & $54(56.3)$ \\
\hline Presence & $42(43.8)$ \\
\hline Pre-IPAA daily prednisolone dose (mg) & $12.5(0-100)$ \\
\hline \multicolumn{2}{|l|}{ LCAP/GCAP } \\
\hline Absence & $59(61.5)$ \\
\hline Presence & 37 (38.5) \\
\hline \multicolumn{2}{|l|}{ Use of immunomodulatory drugs } \\
\hline Absence & $66(68.8)$ \\
\hline Presence & $30(31.3)$ \\
\hline \multicolumn{2}{|l|}{ Post-IPAA steroid use } \\
\hline Absence & $44(45.8)$ \\
\hline Presence & $52(54.2)$ \\
\hline Operating time (min) & $302.5(205-520)$ \\
\hline Blood loss (mL) & $327.0(50-1,204)$ \\
\hline \multicolumn{2}{|l|}{ Surgical procedure } \\
\hline One-stage & $0(0)$ \\
\hline Two-stage & $41(42.7)$ \\
\hline Three-stage & 55 (57.3) \\
\hline \multicolumn{2}{|l|}{ Shape of ileal pouch } \\
\hline$J$ & $15(15.6)$ \\
\hline W & $81(84.4)$ \\
\hline
\end{tabular}

Values are presented as median (range) or number (\%).

IPAA, lleal pouch anal anastomosis; LCAP, leukocytapheresis; GCAP, granulocytapheresis.

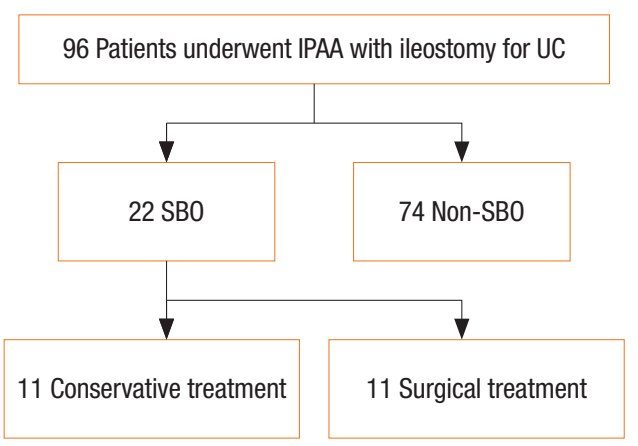

Fig. 1. The outcomes for 96 patients who underwent ileal pouchanal anastomosis with loop ileostomy for ulcerative colitis. IPAA, ileal pouch-anal anastomosis; UC, ulcerative colitis; SBO, small bowel obstruction.
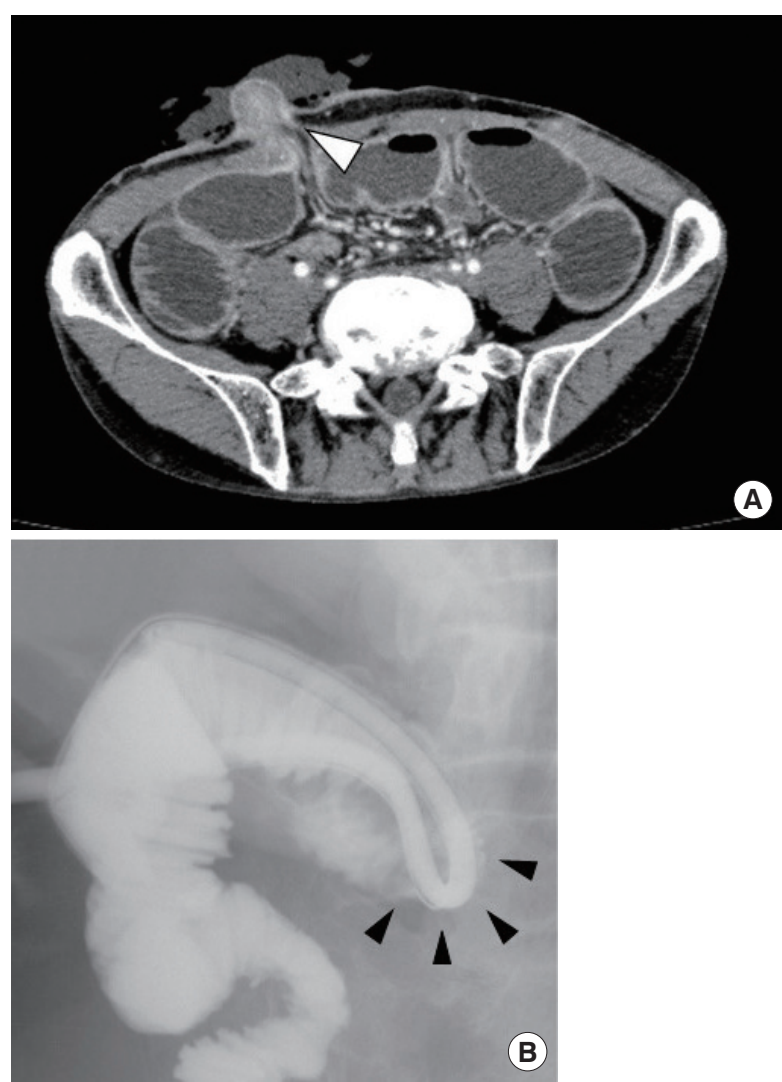

Fig. 2. Diagnosis of small bowel obstruction based on radiographic findings. (A) Computed tomography scan examination shows small intestine stenosis at the level of the abdominal wall (arrowhead) and dilatation of the oral side of the small intestine. (B) Contrast radiography from the transstomal decompression tube shows intestinal pinching at the oral side of the loop ileostomy (arrowheads).

an IPAA with a loop ileostomy in patients with UC (Table 2). No differences were observed in the BMI and the preoperative serum albumin level as parameters used to evaluate the nutritional state. 
Table 2. Patients' characteristics for the SBO and the non-SBO groups

\begin{tabular}{|c|c|c|c|}
\hline \multirow{2}{*}{ Variable } & \multicolumn{2}{|c|}{ Univariate } & \multirow{2}{*}{ P-value } \\
\hline & $\mathrm{SBO}(\mathrm{n}=22)$ & Non-SBO $(n=74)$ & \\
\hline Age (yr) & $25(14-61)$ & $38(15-72)$ & 0.005 \\
\hline Sex & & & 0.028 \\
\hline Male & $16(72.7)$ & $33(44.6)$ & \\
\hline Female & $6(27.3)$ & $41(55.4)$ & \\
\hline Height (cm) & $167.8(155-177)$ & 160.9 (141-183) & 0.003 \\
\hline Weight (kg) & $52.5(38-70)$ & $50.8(34-96)$ & 0.28 \\
\hline Body mass index $\left(\mathrm{kg} / \mathrm{m}^{2}\right)$ & $19.0(15-25)$ & $19.5(14-30)$ & 0.39 \\
\hline Albumin (g/dL) & $4.0(3.6-4.5)$ & $4.0(2.3-5.3)$ & 0.81 \\
\hline Clinical course & & & 0.84 \\
\hline Relapsing-remitting & 17 (77.2) & $53(71.6)$ & \\
\hline Chronic continuous & $2(9.1)$ & $10(13.5)$ & \\
\hline Acute fulminating & $3(13.6)$ & $11(14.9)$ & \\
\hline Surgical indication & & & 0.16 \\
\hline Severe/fulminant & $3(13.6)$ & $25(33.8)$ & \\
\hline Refractory & $14(63.6)$ & $39(52.7)$ & \\
\hline Cancer/dysplasia & $5(22.7)$ & $10(13.5)$ & \\
\hline Pre-IPAA steroid use & & & 0.76 \\
\hline Absence & $5(22.7)$ & $14(18.9)$ & \\
\hline Presence & $17(77.3)$ & $60(81.1)$ & \\
\hline $\begin{array}{l}\text { Total prednisolone dose } \\
\text { (mg) }\end{array}$ & $4,000.0(480-50,000)$ & $6,215.0(0-90,000)$ & 0.35 \\
\hline $\begin{array}{l}\text { Pre-IPAA daily prednis- } \\
\text { olone dose (mg) }\end{array}$ & $10.8(0-80)$ & $15.0(0-100)$ & 0.23 \\
\hline LCAP/GCAP & & & 0.81 \\
\hline Absence & $13(59.1)$ & $46(62.2)$ & \\
\hline Presence & $9(40.9)$ & $28(37.8)$ & \\
\hline $\begin{array}{l}\text { Use of immunomodula- } \\
\text { tory drugs }\end{array}$ & & & 0.12 \\
\hline Absence & $12(54.5)$ & $54(73.0)$ & \\
\hline Presence & $10(45.5)$ & $20(27.0)$ & \\
\hline Post-IPAA steroid use & & & 0.15 \\
\hline Absence & $7(31.8)$ & $38(51.4)$ & \\
\hline Presence & 15 (68.2) & $36(48.6)$ & \\
\hline Operating time (min) & $310.5(235-457)$ & $300.0(205-520)$ & 0.47 \\
\hline Blood loss (mL) & 220.0 (70-985) & $345.5(50-1,204)$ & 0.085 \\
\hline Surgical procedure & & & 0.029 \\
\hline Two-stage & 14 (63.6) & 27 (36.5) & \\
\hline Three-stage & $8(36.4)$ & 47 (63.5) & \\
\hline Stoma rotation & & & $>0.99$ \\
\hline Yes & $5(22.7)$ & $18(24.3)$ & \\
\hline No & 17 (77.3) & $56(75.7)$ & \\
\hline
\end{tabular}

Table 2. Continued

\begin{tabular}{lccc}
\hline \multirow{2}{*}{ Variable } & \multicolumn{2}{c}{ Univariate } & \multirow{2}{*}{ P-value } \\
\cline { 2 - 3 } & $\mathrm{SB}(\mathrm{n}=22)$ & Non-SB0 $(\mathrm{n}=74)$ & 0.32 \\
\hline Shape of pouch & $5(22.7)$ & $10(13.5)$ & \\
$\mathrm{J}$ & $17(77.3)$ & $64(86.5)$ & \\
W & & & 0.22 \\
$\begin{array}{l}\text { Adhesion barrier mem- } \\
\text { brane }\end{array}$ & $14(63.6)$ & $34(45.9)$ & \\
$\quad$ Yes & $8(36.4)$ & $40(54.1)$ & \\
$\quad$ No & $10.0(5.0-17.0)$ & $8.0(5.0-19.0)$ & 0.094 \\
$\begin{array}{l}\text { Thickness of RM (mm) } \\
\text { Thickness of fat (mm) }\end{array}$ & $17.3(4.9-31.4)$ & $16.7(5.2-201.0)$ & 0.77 \\
$\begin{array}{l}\text { Stoma size at skin level } \\
\text { (mm) }\end{array}$ & $15.6(12.4-20.2)$ & $16.9(9.2-26.3)$ & 0.76 \\
$\begin{array}{l}\text { Stoma size at fascia } \\
\text { level (mm) }\end{array}$ & $12.5(8.5-23.1)$ & $12.0(7.6-21.8)$ & 0.93 \\
\hline
\end{tabular}

Values are presented as median (range) or number (\%).

SBO, small bowel obstruction; IPAA, ileal pouch anal anastomosis; LCAP, leukocytapheresis; GCAP, granulocytapheresis; RM, rectus abdominis muscle.

The median thickness of the abdominal rectus muscle was 10.0 $\mathrm{mm}$ in the SBO group and $8.0 \mathrm{~mm}$ in the non-SBO group. In addition, the thickness of the subcutaneous fat was $17.3 \mathrm{~mm}$ in the $\mathrm{SBO}$ group and $16.7 \mathrm{~mm}$ in the non-SBO group. These parameters on the CT scan image were not significantly different between the 2 groups. The parameters of stoma size at the skin or the fascia level on the CT scan were also not significantly different. In the multivariate logistic regression analysis, the 2-stage procedure (odds ratio, 2.850; 95\% confidence interval, 1.009-8.044; $\mathrm{P}=$ 0.048 ) was a significant independent risk factor of a SBO after an IPAA with a loop ileostomy in patients with UC (Table 3).

\section{DISCUSSION}

A SBO remains a common complication after pelvic or abdominal surgery. A previous report noted that a SBO after abdominal surgery occurred in approximately $20 \%$ of the patients [1]. The risk of a SBO is greater, in particular, after colorectal surgery [21]. The TPC with an IPAA has become the standard surgical approach for treating patients with $\mathrm{UC}$. The incidence of a SBO after an IPAA for UC is higher than that observed with other types of abdominal surgery. As the IPAA may be considered a high-risk procedure for developing a SBO, it can be combined with a wide abdominal and pelvic dissection and may be performed as a staged surgical procedure. Moreover, a diverting loop ileostomy is associated with an increased risk of a SBO $[7,16]$.

In the present study, the incidence of a $\mathrm{SBO}$ in the pretakedown of a loop ileostomy after an IPAA was $22.9 \%$ (22 patients). Furthermore, of these 22 patients, 11 required surgical intervention. 
Table 3. Multivariate logistic analysis of the risk factors for SBO after IPAA in patients with ulcerative colitis

\begin{tabular}{|c|c|c|c|c|}
\hline \multirow{2}{*}{ Variable } & \multicolumn{2}{|c|}{ Univariate } & \multicolumn{2}{|c|}{ Multivariate } \\
\hline & Odds ratio $(95 \% \mathrm{Cl})$ & P-value & Odds ratio (95\% Cl) & P-value \\
\hline Age (<35 yr) & $2.297(0.860-6.138)$ & 0.144 & $2.104(0.712-6.221)$ & 0.179 \\
\hline Male sex & $3.046(1.015-1.659)$ & 0.029 & $2.477(0.582-10.537)$ & 0.219 \\
\hline Height ( $\geq 162 \mathrm{~cm})$ & $3.313(1.166-9.413)$ & 0.028 & $1.594(0.369-6.883)$ & 0.532 \\
\hline Surgical procedure (2-stage procedure) & $3.046(1.133-8.192)$ & 0.029 & $2.850(1.009-8.044)$ & 0.048 \\
\hline
\end{tabular}

SBO, small bowel obstruction; IPAA, ileal pouch anal anastomosis; $\mathrm{Cl}$, confidence interval.

Table 4. Characteristics of the patients in the 2-stage procedure and the 3-stage procedure groups

\begin{tabular}{|c|c|c|c|}
\hline \multirow{2}{*}{ Variable } & \multicolumn{2}{|c|}{ Univariate } & \multirow{2}{*}{ P-value } \\
\hline & Two-stage $(n=41)$ & Three-stage $(n=55)$ & \\
\hline Surgical indication & & & $<0.001$ \\
\hline Severe/fulminant & $3(7.3)$ & $25(45.5)$ & \\
\hline Refractory & $24(58.5)$ & $29(52.7)$ & \\
\hline Cancer/dysplasia & $14(34.1)$ & $1(1.8)$ & \\
\hline Total prednisolone dose (mg) & $7,500(0-90,000)$ & $2,000(480-22,000)$ & 0.45 \\
\hline Pre-IPAA steroid use & & & 0.44 \\
\hline Absence & $10(24.4)$ & $9(16.4)$ & \\
\hline Presence & $31(75.6)$ & $46(83.6)$ & \\
\hline Pre-IPAA daily prednisolone dose (mg) & $10.0(0-35)$ & $30.0(0-100)$ & $<0.001$ \\
\hline
\end{tabular}

Values are presented as number (\%) or median (range).

IPAA, ileal pouch anal anastomosis.

We had to close the ileostomy earlier than expected. The cause of surgical intervention in 8 of the 11 patients was an outlet obstruction at the level of the abdominal wall. In general, surgical treatment for a SBO should be considered when the patient's symptoms do not resolve within 6 days of nasogastric decompression $[21,22]$. The incidence of a SBO is not rare after an IPAA with a loop ileostomy for patients with UC. If the SBO does not improve after conservative treatment, due consideration should be given to an earlier closure of the ileostomy.

In our study, we also evaluated the relationship between the parameters on the CT scan image and the incidence of a SBO after an IPAA in patients with UC. We measured some parameters on the CT scan image, such as the thickness of the abdominal rectus muscle, the thickness of the subcutaneous fat, and the size of the stoma at the skin or fascia level. Even though no statistically significant differences in these parameters from the CT scan image with respect to the incidence of a SBO after an IPAA with a loop ileostomy were seen in our study, the thickness of the abdominal rectum muscle may be a risk factor of a SBO $(\mathrm{P}=0.094)$.

The current study showed that a 2-stage procedure is an independent risk factor for a SBO after an IPAA with a loop ileostomy in patients with UC. MacLean et al. [11] also reported that the rate of a SBO occurring in patients who had their colectomy performed before the IPAA procedure was lower. Our study corrobo- rated these results. The reason for the difference in the incidence of a SBO between the 2- and the 3-step procedures may be partly due to the steroid dose. A previous report noted that the incidence of a SBO in the 3-stage procedure was lower because a high dose of steroids may reduce the risk of adhesions [11]. In our study, the median total dose of prednisolone before the IPAA was $7,500 \mathrm{mg}$ for patients undergoing the 2-stage procedure and 2,000 $\mathrm{mg}$ for the patients undergoing the 3 -stage procedure $(\mathrm{P}=0.45)$. However, the pre-IPAA daily prednisolone dose for the patients undergoing the 3-stage procedure was higher than that of the patients undergoing the 2-stage procedure (Table 4 ). No difference in the use of perioperative steroids was observed between the SBO and the non-SBO groups (Table 2). Therefore, further investigation is required to understand the effect of a difference in steroid use on the incidence of a SBO.

Recently, laparoscopic surgery has been more frequently used for UC than open surgery has [23-26]. The laparoscopic TPC with an IPAA is feasible and may provide better short-term advantages, including a shorter duration of hospital stay and a lower rate of complications [24]. A laparoscopic approach may result in decreased adhesion formation and a lower risk of a subsequent SBO [11]. However, Dolejs et al. [25] stated that the incidences of a SBO were $7 \%$ after open surgery and $13 \%$ after laparoscopic surgery in patients with UC. Furthermore, El-Gazzaz et al. [26] 
noted that the incidences of a SBO after open and laparoscopic surgeries were $4 \%$ and $6 \%$, respectively. These authors considered the intestine to be potentially more prone to mechanical kinking or twisting at the ileostomy site because fewer adhesions were generated during laparoscopic surgery. However, they also stated that the laparoscopic group may have a lower incidence of SBO over a longer period.

A diverting loop ileostomy is also a risk factor for a SBO. In this study, the cause of the SBO in eight patients was considered to be an outlet obstruction. Of these patients, 6 had undergone a 2-stage procedure. We consider the loop ileostomy to be one of the main causes of an outlet obstruction. In general, the procedure of the IPAA without a diverting ileostomy may increase anastomotic leakage [27]. However, an IPAA without a protective ileostomy is a safe option in the pediatric population and is not associated with increased morbidity [6]. Therefore, the omission of a covering ileostomy may still be justified in patients defined as low risk.

As ways to prevent a SBO after surgery, several clinical studies reported that employment of a sodium hyaluronate-based bioresorbable membrane (Seprafilm; Genzyme Corp., Cambridge, MA, USA) markedly reduced the incidence and the severity of adhesions after abdominal surgery, although we did not observe any differences in adhesion barrier use in our study [28]. The intraluminal pressure of the small intestine is estimated to be $6-13$ $\mathrm{mmHg}$ and that of the colon to be $10-30 \mathrm{mmHg}[29,30]$. Considering that the intraluminal pressure of the small intestine is lower than that of the colon, a possibility exists that relative stenosis in the abdominal wall level may have occurred [29]. Consequently, making an abdominal wall opening of sufficient size to prevent a "pinching" effect and edema is important [12]. However, determining an appropriate stoma size in this study was difficult.

The rotation of the loop ileostomy is believed to facilitate emptying into the appliance and to prevent spillage into the efferent limb protecting the anastomosis. However, rotated and nonrotated loop ileostomies are equally effective in division. Indeed, rotation of the loop ileostomy is a risk factor for intestinal obstruction. The incidence of obstruction in patients with rotated ileostomies was nearly twice that in patients with nonrotated iloestomies [16]. We consider that stoma rotation may induce twisting of the small intestine. Therefore, we have not performed a recent rotation of the loop ileostomy.

Our study has several limitations. It was a retrospective study with a small sample size. Furthermore, the backgrounds of the patients who underwent the 2 - and the 3-stage procedures were different (Table 4). The differences in the variables between the 2 groups may be due to the selection bias when performing the operation because we selected the 3-stage procedure for patients with severe conditions, like severe/fulminant type UC. In addition, a SBO in this study included an outlet obstruction and adhesive ileus as the reason for the obstruction. In this study, the cause of the SBOs requiring surgery was "outlet obstruction" in 8 patients. In the remaining three patients, the cause of the SBO was considered to be intra-abdominal adhesion. However, clearly distinguishing between these 2 causes is difficult. Nevertheless, our study has demonstrated new and significant findings related to the risk factors associated with the ileostomy pretakedown period after an IPAA in patients with UC. In conclusion, the present study revealed that the 2-stage procedure is a significant and independent risk factor of a SBO occurring after an IPAA with a loop ileostomy in patients with UC.

\section{CONFLICT OF INTEREST}

No potential conflict of interest relevant to this article was reported.

\section{REFERENCES}

1. Siporin K, Hiatt JR, Treiman RL. Small bowel obstruction after abdominal aortic surgery. Am Surg 1993;59:846-9.

2. Menzies D, Ellis H. Intestinal obstruction from adhesions: how big is the problem? Ann R Coll Surg Engl 1990;72:60-3.

3. Aberg H, Påhlman L, Karlbom U. Small-bowel obstruction after restorative proctocolectomy in patients with ulcerative colitis. Int J Colorectal Dis 2007;22:637-42.

4. Parks AG, Nicholls RJ. Proctocolectomy without ileostomy for ulcerative colitis. Br Med J 1978;2:85-8.

5. Utsunomiya J, Iwama T, Imajo M, Matsuo S, Sawai S, Yaegashi K, et al. Total colectomy, mucosal proctectomy, and ileoanal anastomosis. Dis Colon Rectum 1980;23:459-66.

6. Ryan DP, Doody DP. Restorative proctocolectomy with and without protective ileostomy in a pediatric population. J Pediatr Surg 2011;46:200-3.

7. Chaudhary P, Nabi I, Ranjan G, Tiwari AK, Kumar S, Kapur A, et al. Prospective analysis of indications and early complications of emergency temporary loop ileostomies for perforation peritonitis. Ann Gastroenterol 2015;28:135-40.

8. Ellis $\mathrm{H}$. The clinical significance of adhesions: focus on intestinal obstruction. Eur J Surg Suppl 1997;(577):5-9.

9. Edna TH, Bjerkeset T. Small bowel obstruction in patients previously operated on for colorectal cancer. Eur J Surg 1998;164:58792.

10. Patil V, Vijayakumar A, Ajitha MB, Kumar LS. Comparison between Tube Ileostomy and Loop Ileostomy as a Diversion Procedure. ISRN Surg 2012;2012:547523.

11. MacLean AR, Cohen Z, MacRae HM, O’Connor BI, Mukraj D, Kennedy ED, et al. Risk of small bowel obstruction after the ileal pouch-anal anastomosis. Ann Surg 2002;235:200-6.

12. Francois Y, Dozois RR, Kelly KA, Beart RW Jr, Wolff BG, Pemberton JH, et al. Small intestinal obstruction complicating ileal pouch-anal anastomosis. Ann Surg 1989;209:46-50.

13. Oresland T, Fasth S, Nordgren S, Hultén L. The clinical and func- 
tional outcome after restorative proctocolectomy. A prospective study in 100 patients. Int J Colorectal Dis 1989;4:50-6.

14. McMullen K, Hicks TC, Ray JE, Gathright JB, Timmcke AE. Complications associated with ileal pouch-anal anastomosis. World J Surg 1991;15:763-6.

15. Poppen B, Svenberg T, Bark T, Sjögren B, Rubio C, Drakenberg B, et al. Colectomy-proctomucosectomy with S-pouch: operative procedures, complications, and functional outcome in 69 consecutive patients. Dis Colon Rectum 1992;35:40-7.

16. Marcello PW, Roberts PL, Schoetz DJ Jr, Coller JA, Murray JJ, Veidenheimer MC. Obstruction after ileal pouch-anal anastomosis: a preventable complication? Dis Colon Rectum 1993;36:110511.

17. Fazio VW, Ziv Y, Church JM, Oakley JR, Lavery IC, Milsom JW, et al. Ileal pouch-anal anastomoses complications and function in 1005 patients. Ann Surg 1995;222:120-7.

18. Beck DE, Opelka FG, Bailey HR, Rauh SM, Pashos CL. Incidence of small-bowel obstruction and adhesiolysis after open colorectal and general surgery. Dis Colon Rectum 1999;42:241-8.

19. Hatakeyama K, Yamai K, Muto T. Evaluation of ileal W pouchanal anastomosis for restorative proctocolectomy. Int J Colorectal Dis 1989;4:150-5.

20. Maruta T, Homma S, Yagi M, Hasegawa J, Shimamura K, Suda T, et al. Key factors influencing bowel function after ileal W-pouch anal anastomosis: a spectral analysis of W-pouch motor activity. Surg Today 2000;30:886-91.

21. Stewart RM, Page CP, Brender J, Schwesinger W, Eisenhut D. The incidence and risk of early postoperative small bowel obstruction. A cohort study. Am J Surg 1987;154:643-7.
22. Ellozy SH, Harris MT, Bauer JJ, Gorfine SR, Kreel I. Early postoperative small-bowel obstruction: a prospective evaluation in 242 consecutive abdominal operations. Dis Colon Rectum 2002;45: 1214-7.

23. White I, Jenkins JT, Coomber R, Clark SK, Phillips RK, Kennedy RH. Outcomes of laparoscopic and open restorative proctocolectomy. Br J Surg 2014;101:1160-5.

24. Hata K, Kazama S, Nozawa H, Kawai K, Kiyomatsu T, Tanaka J, et al. Laparoscopic surgery for ulcerative colitis: a review of the literature. Surg Today 2015;45:933-8.

25. Dolejs S, Kennedy G, Heise CP. Small bowel obstruction following restorative proctocolectomy: affected by a laparoscopic approach? J Surg Res 2011;170:202-8.

26. El-Gazzaz GS, Kiran RP, Remzi FH, Hull TL, Geisler DP. Outcomes for case-matched laparoscopically assisted versus open restorative proctocolectomy. Br J Surg 2009;96:522-6.

27. Weston-Petrides GK, Lovegrove RE, Tilney HS, Heriot AG, Nicholls RJ, Mortensen NJ, et al. Comparison of outcomes after restorative proctocolectomy with or without defunctioning ileostomy. Arch Surg 2008;143:406-12.

28. Kusunoki M, Ikeuchi H, Yanagi H, Noda M, Tonouchi H, Mohri Y, et al. Bioresorbable hyaluronate-carboxymethylcellulose membrane (Seprafilm) in surgery for rectal carcinoma: a prospective randomized clinical trial. Surg Today 2005;35:940-5.

29. FINK S. The intraluminal pressures in the intact human intestine. Gastroenterology 1959;36:661-71.

30. Painter NS, Truelove SC. The intraluminal pressure patterns in diverticulosis of the colon. I. Resting patterns of pressure. II. The effect of morphine. Gut 1964;5:201-13. 